\title{
LOTEAMENTO DE INTERESSE SOCIAL E A EXPANSÃO URBANA EM SANTO ANASTÁCIO - SP
}

Thiago Yugo Nagai Matsutane ${ }^{1}$, Mayara Pissuti Albano ${ }^{1}$, Sibila Corral de Arêa Leão Honda ${ }^{2}$, Patrícia Reiners Carvalho ${ }^{1}$

${ }^{1}$ Universidade do Oeste Paulista - UNOESTE, curso de Arquitetura e Urbanismo, Presidente Prudente, SP. ${ }^{2}$ Arquiteta Urbanista, Global Planejamento. E-mail: ma.albano@unoeste.br

\section{RESUMO}

O recente e rápido processo de urbanização brasileiro colaborou para a existência de diversos problemas urbanos, sendo que a segregação sócioespacial corresponde a um dos mais graves. 0 processo segregador intra-urbano estimula a desigualdade de acesso aos benefícios da urbanização, tais como saneamento ambiental adequado, transporte público, equipamentos públicos de saúde e educação, entre outros. Conhecer a realidade das cidades constitui uma importante base para o desenvolvimento de diretrizes de planejamento e gestão urbanos. 0 presente trabalho tem por objetivo apresentar o levantamento dos conjuntos habitacionais e sua relação com a estruturação intra-urbana da cidade de Santo Anastácio, localizada no interior do estado de São Paulo. A metodologia seguida nesta pesquisa se apoia levantamentos bibliográficos, documentais e de campo.

Palavras-chave: Evolução da malha urbana. Expansão territorial urbana. Planejamento urbano. Habitação de Interesse social. Santo Anastácio -SP.

\section{SOCIAL LOT AND URBAN EXPANSION IN SANTO ANASTÁCIO - SP}

\begin{abstract}
The recent and rapid process of Brazilian urbanization contributed to the existence of several urban problems, and the socio-spatial segregation corresponds to one of the most serious. The intra-urban segregation process stimulates unequal access to the benefits of urbanization, such as adequate environmental sanitation, public transportation, public health and education equipment, among others. Knowing the reality of cities constitutes an important basis for the development of urban planning and management guidelines. The objective of this study is to present a survey of the housing complexes and their relationship with the intra-urban structuring of the city of Santo Anastácio, located in the interior of the state of São Paulo. The methodology followed in this research supports bibliographical, documentary and field surveys.
\end{abstract}

Keywords: Evolution of the urban network. Urban territorial expansion. Urban planning. Social Habitation. Santo Anastácio - SP.

\section{INTRODUÇÃO}

O recente processo de urbanização brasileiro ocasionou uma série de dificuldades no que diz respeito à gestão e ao planejamento urbanos, bem como à organização territorial municipal (HONDA, 2011). Conhecer a estrutura intra-urbana se faz necessário para que diretrizes de planejamento e gestão urbanos sejam desenvolvidas sobre uma base concreta, observando as particularidades de cada cidade.

Segundo Santos (1993), as cidades de todo o Brasil possuem problemas semelhantes relacionados ao modelo de estruturação da malha urbana que, entre outros problemas, 
desencadeiam acentuada segregação socioespacial. Essa estrutura é influenciada, não exclusivamente, mas em grande parte, pela camada de alta renda e pelo mercado imobiliário, que investem nas áreas onde se instalam, aumentando o valor do solo local dotando-a de boa infraestrutura, acessibilidade, mobilidade, que acabam por enfatizar as desigualdades em relação às áreas ocupadas pelas classes de baixa renda (VILLAÇA, 1998).

Outro agente que têm interferido significativamente ao longo das últimas décadas na estrutura urbana, colaborando com a acentuação da segregação, é o poder público, responsável pela implementação de políticas de habitação social (ALBANO, 2013).

$\mathrm{Na}$ década de 1990, segundo Maricato (2008, p.5), havia "uma proposta sensível e atualizada com as análises técnicas e críticas" sobre políticas habitacionais, com preocupação com questões fundiárias e urbanísticas, visando à ocupação de vazios urbanos.

Em 2009, foi lançado o Programa Minha Casa Minha Vida - PMCMV, com o objetivo de subsidiar produção e aquisição de imóvel urbano para famílias com renda de até seis salários mínimos mensais, buscando a construção de 1 milhão de moradias segundo dados do website oficia do Governo Federal. Segundo critérios, o PMCMV financiaria imóveis residenciais nos municípios em que houvesse doação de terrenos e/ou glebas pelo poder público local ou estadual. Dessa forma, muitas das áreas ocupadas pelos conjuntos habitacionais têm proporcionado a expansão territorial, inclusive com a implantação além malha urbana (HONDA, 2011).

Com base nesse contexto, o presente artigo visa a analisar o crescimento urbano da cidade de Santo Anastácio, no interior do estado de São Paulo, por meio de levantamento histórico e análise da estruturação intra-urbana, para tanto, busca-se compreender o processo de expansão territorial da cidade de Santo Anastácio, no interior do Estado de São Paulo, por meio da implantação de empreendimentos - loteamentos e conjuntos habitacionais - públicos e particulares na malha urbana dessa cidade, no período de 1989 e 2016.

\section{METODOLOGIA}

A primeira etapa metodológica realizada foi baseada em aprofundamento teórico e bibliográficos, por meio de levantamentos históricos sobre a formação e crescimento da cidade, aspectos econômicos e sociais. Posteriormente foram realizados levantamentos documentais para organizar dados disponíveis em jornais, cartório de registro de imóveis e Prefeitura Municipal, visando a formar uma base de informações que subsidiem o mapeamento da evolução da malha urbana. Também foi realizada pesquisa de campo para identificação de tipologias construtivas e existência/carência de infraestrutura urbana, apoiando compreensão sobre localização de bairros de diferentes classes sociais.

\section{A PRODUÇÃO DO ESPAÇO INTRA-URBANO}

O processo de produção de cidades e de crescimento urbano foi significativamente marcante a partir da década de 1960, no Brasil. Verifica-se, além da expansão de grandes centros urbanos, o desenvolvimento de cidades médias e pequenas, mas seguindo o padrão de especulação intra-urbana (SANTOS, 1998).

Segundo Villaça (1998), há segregação de várias naturezas, principalmente de classes e de etnias ou nacionalidades; mas a que domina o território urbano brasileiro é a de classes sociais. Este tipo específico de segregação é definido pelo autor como: "um processo segundo o qual diferentes classes ou camadas sociais tendem a se concentrar cada vez mais em diferentes regiões gerais ou conjuntos de bairros" (VILLAÇA, 1998, p.142).

Nesse contexto, verificam-se diversos atores na produção do espaço urbano, que podem reforçar (ou não) os processos de segregação e de especulação; ou seja, as ações dos atores 
refletem os interessem dominantes, permitindo "transgressões de acordo com os interesses" (CORRÊA, 1999, p.12).

Um desses agentes é o Estado, que atua na organização espacial da cidade, por meio da implantação de serviços públicos e da elaboração de leis e normas vinculadas ao solo urbano, e que reflete a dinâmica da sociedade e os interesses dominantes (HONDA, 2011). Importante destacar que é na instância municipal onde esses interesses se tornam mais evidentes. Corrêa $(1999$, p.26) assinala que a atuação do Estado busca criar "condições que viabilizem o processo de acumulação e a reprodução das classes sociais e suas frações", assim o Estado cria mecanismos que podem levar à segregação espacial.

Essa ação do Estado é informada por meio de políticas públicas, desenvolvidas em resposta a problemas urbanos, desde a previsão de bens coletivos e serviços públicos até o controle da expansão urbana, e uso e ocupação do solo; sendo identificada como o setor de ordenamento legal do território das cidades através de conjunto de ações descritas, com a observação das demandas e a tentativa de harmonização (HONDA, 2011).

Nesse cenário, verifica-se a importância de levantamentos, mapeamentos e identificação de manchas de ocupação populacional na cidade de Santo Anastácio, no interior do estado de São Paulo, possibilitando a compreensão dos processos intra-urbanos de ocupação territorial.

O planejamento, entendido como tentativa de "prever a evolução de um fenômeno ou [...] tentar simular os desdobramentos de um processo" (SOUZA, 2008, p.46), pode ser ferramenta de auxílio na democratização de acesso ao solo urbano e de benefícios da urbanização, que afetam diretamente a qualidade de vida da população, ou como afirma Souza (2008, p.61):

[...] um autêntico processo de desenvolvimento sócio-espacial quando se constata uma melhoria da qualidade de vida e um aumento da justiça social. A mudança social positiva, no caso, precisa contemplar não apenas as relações sociais, mas, igualmente, a espacialidade.

Por meio da apreensão da realidade urbana de Santo Anastácio, assim como das ações públicas de planejamento territorial, será possível compreender o processo de urbanização e de mudanças morfológicas urbanas que têm ocorrido nessa cidade. Lacaze $(1995$, p.18) informa que "As investigações de morfologia urbana, associando o olhar do arquiteto a trabalhos sobre os arquivos escritos e os planos antigos, tornam possíveis análises muito precisas".

\section{SANTO ANASTÁCIO - ESTUDO DE CASO}

\section{A produção do espaço intra-urbano de Santo Anastácio.}

Santo Anastácio é uma cidade de pequeno porte, com aproximadamente 21.044 mil habitantes. Localiza-se no Estado de São Paulo, na região oeste conhecida como Alta Sorocabana, onde se concentram uma alta quantidade de atividades agropecuárias (IBGE, 2016).

Em 1936 o prefeito municipal Ariosto Orsine, em seu relatório demonstrou preocupações sobre a necessidade de um plano de urbanização da cidade de Santo Anastácio, "o ideal seria a elaboração de um plano geral de urbanismo, realizado por técnico, para se the ir dando aplicação por partes". A malha urbana da cidade não é irregular, suas quadras e infraestrutura foram planejadas, como alguns requisitos, as principais ruas e avenidas largas, fazendo seu traçado de forma homogênea e também um plano de arborização (JALOTO e JUNIOR, 1995).

Porém à medida em que a malha urbana foi desenvolvendo ela não acompanhou de forma regular como havia sido iniciada, e o plano de arborização não foi preservado, em meados dos anos 1960, a influência do urbanismo moderno, foi retirado boa parte da arborização das cidades (JALOTO e JUNIOR, 1995). 
A área planejada do município de Santo Anastácio é justamente onde se deu origem o centro da cidade e concomitantemente, o local onde a classe dominante ocupava. Isso se assemelha ao abordado por Villaça (1998), onde o autor enfatiza que nas cidades brasileiras, em especial, a classe dominante sempre ocupava os lugares mais privilegiados.

O município de Santo Anastácio, como cidade interiorana, cresce em todas as direções, todavia, se expandiu de uma forma significativa na direção sul onde se concentra a maior parte da população, já na direção norte, pouco se desenvolve (JALOTO e JUNIOR, 1995). Assim como em outras cidades estudadas por Villaça (1998), a ferrovia se torna uma barreira dentro da cidade, ou seja, um lado se concentram as principais atividades comerciais da cidade, geralmente tendo em vista os locais mais vantajosos, com uma topografia menos acentuada.

Outro fator que influenciou a expansão na direção sul é a relação interurbana, onde a implementação da Rodovia Raposo Tavares trouxe uma melhoria em relação a acessibilidade e comunicação, com isso a valorização do local influenciando ainda mais o crescimento da cidade nessa direção. Maricato (2008) afirma que o automóvel trouxe uma mudança significativa no modo de vida das pessoas, desde valores, culturas e rotinas. Isso influenciou também a cidade de Santo Anastácio, que apresenta mudanças no modo de vida da população, como também mudança na cidade e nas direções de expansão urbana.

A Vila Oriente, é o único Bairro existente da cidade na direção norte, ou seja, na área desvantajosa até os dias atuais, tomado pelo desinteresse da classe dominante pelo local, o bairro comporta um único clube, as demais edificações possuem uso residencial.

\section{Santo Anastácio e a habitação social}

Após a formação da área central da cidade, em 1982 e 1984 foi inaugurado os dois primeiros conjuntos habitacionais do município de Santo Anastácio, Jardim Vitória Régia que fica ao lado direito do centro e o Jardim Nosso teto, que fica afastado do centro na direção sul as margens da rodovia Raposo Tavares (Levantamento de registro Da fundação de Bairros realizado pelo cartório de registro de imóveis do Município de Santo Anastácio -SP). 
Figura 1 - Conjuntos habitacionais em Santo Anastácio - SP.

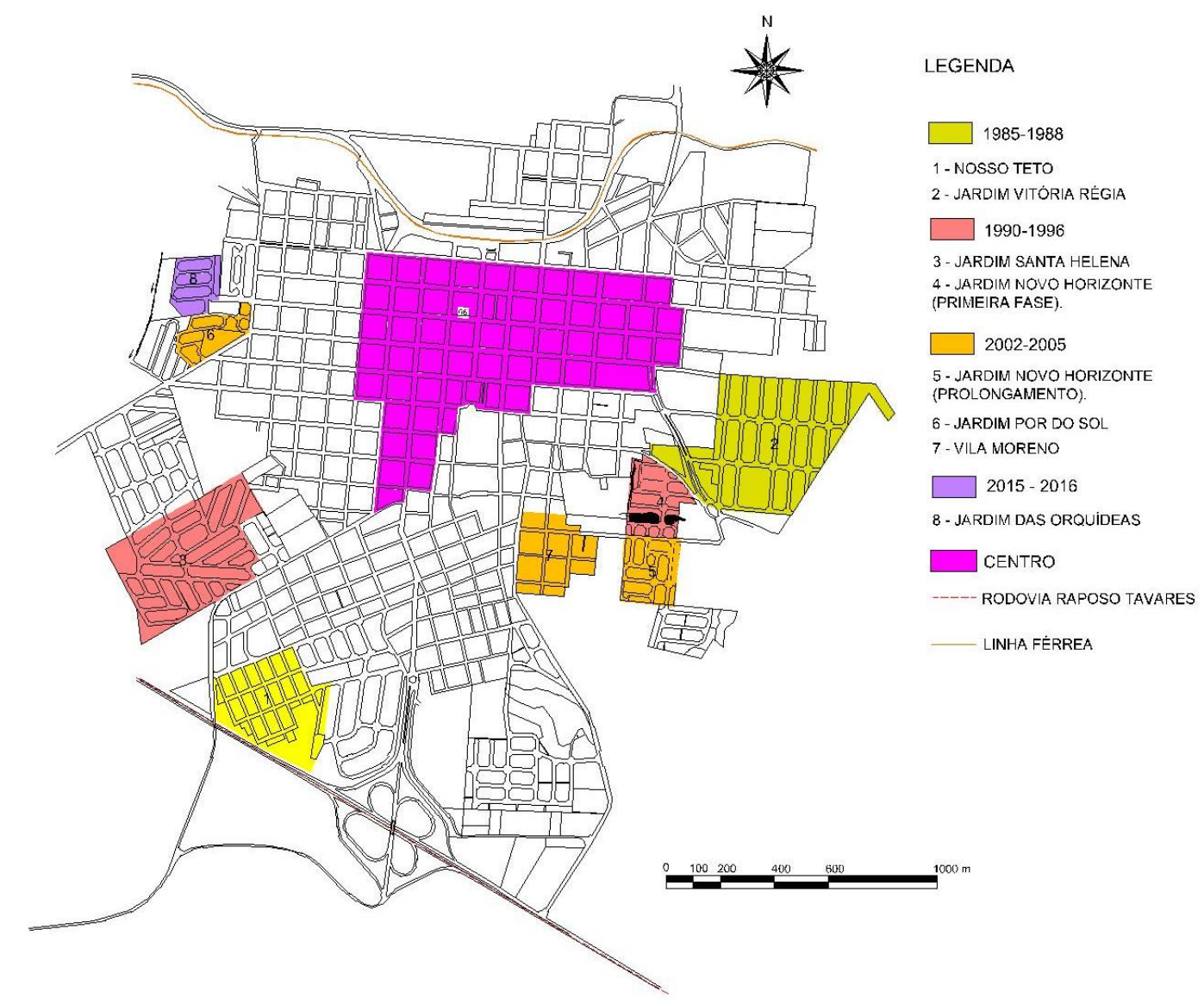

FONTE: Prefeitura Municipal de Santo Anastácio -SP, Cartório de Registro de Imóveis de Santo Anastácio. Modificado pelos autores (2017).

O Jardim Vitória Régia foi construído em um regime de mutirão, onde os próprios moradores que adquiriam o terreno juntavam amigos e familiares para construírem suas casas, sem nenhum tipo de apoio técnico, viabilizando a obtenção dos materiais de construção, e assim, erguendo as suas casas. Seguindo o exemplo nacional, destacado por Maricato (2015, p. 26):

As cidades são evidências notáveis dessa formulação teórica, e, nelas, o melhor exemplo talvez seja a construção da moradia (e parte das cidades) pelos próprios trabalhadores (trabalhadores de baixa renda). Essa construção se dá aos poucos, durante seus horários de folga, ao longo de muitos anos, ignorando toda e qualquer legislação urbanística, em áreas ocupadas informalmente.

No entanto, houve diversos problemas e reclamações por parte da população que os terrenos não foram sorteados de forma devida, entregando-os para famílias que não possuíam de fato tal necessidade ${ }^{1}$. A autoconstrução evidencia que a habitação dos trabalhadores não é considerada problema ou preocupação para os interesses capitalistas, nem mesmo para o Estado (MARICATO, 2015).

No caso do Jardim Nosso Teto, que na sua origem foi construído na franja urbana demonstra uma tendência ao início do processo de segregação territorial, enquanto a classe mais alta reside nas áreas centrais, privilegiadas pela proximidade e acesso fácil ao serviço e ao

\footnotetext{
${ }^{1}$ Reportagem do Jornal Oeste Notícias, 1998.

Colloquium Socialis, Presidente Prudente, v. 01, n. Especial 2, Jul/Dez, 2017, p.794-800. DOI: 10.5747/cs.2017.v01.nesp2.s0230
} 
comércio; os moradores do conjunto que são de classe baixa, não desfrutam do mesmo privilégio, tendência destacada por Maricato (2008) nas cidades brasileiras como um todo.

Já entre 1985 e 1992 começaram a surgir bairros novos, sendo estes: Vila Sanches Postigo que fica próximo ao Jardim Nosso Teto; Vila Ortega e Vila Martins que fica próximo ao Centro; e por fim Jardim Maringá e o Solar das Andorinhas que se encontra na direção oeste ${ }^{2}$.

Entre 1993 e 2006, foram implantados mais três conjuntos habitacionais, sendo em sequência: Jardim Santa Helena, localizada no lado oeste da cidade; Jardim Novo Horizonte, que está implantado no lado leste da cidade, onde, posteriormente recebeu um prolongamento do conjunto habitacional em 2002 adicionando mais unidades, dividindo assim Novo Horizonte 1 e 2, sendo esses dois conjuntos separados por uma bacia hidrográfica; e por fim a Vila Moreno que fica próximo ao Novo Horizonte. De 2011 até 2016 foi implantado também mais alguns bairros e o mais recente conjunto habitacional, o Jardim das Orquídeas que está situado na franja urbana da região oeste ${ }^{3}$.

Villaça (1998), afirma que o "funcionamento da sociedade urbana transforma seletivamente os lugares", isto é, alguns pontos das cidades se tornam mais atrativos do que outros, e consequentemente, tudo o que traz aglomeração em um determinado ponto, gera afastamento em outro, de modo a promover uma distribuição desigual dos investimentos em infraestrutura. Na Vila Oriente, o único bairro localizado na direção sul após a linha férrea, nota-se que, por ser "desvantajoso" para o mercado imobiliário, há uma presença significativa de ocupações irregulares, com ausência de infraestrutura adequada.

Em Santo Anastácio, ao analisar a localização dos bairros destinados a habitações de interesse social, a organização do espaço urbano através da separação das classes fica nítida, enquanto na área central estão localizadas as camadas da população de mais alta renda, nas áreas periféricas, as de baixa renda.

\section{CONCLUSÃO}

Através dos estudos e levantamentos realizados, foi possível notar a perpetuação do modelo brasileiro de produção do espaço urbano, onde, mesmo se tratando de uma cidade de porte pequeno, no interior do estado de São Paulo, apresenta claramente a diferenciação dos espaços onde residem as diferentes classes sociais. Os bairros destinados aos mais ricos se encontram próximos à maior concentração de comércios e serviços, e em contrapartida, a população de baixa renda vive em conjuntos habitacionais e em bairros mais distantes do centro.

\section{REFERÊNCIAS BIBLIOGRÁFICAS}

ALBANO, Mayara Pissutti. A importância do Planejamento Urbano Ambiental: a habitação social e a expansão urbana em Presidente Prudente-SP. Dissertação (Mestrado) - Universidade do Oeste Paulista, Presidente Prudente, 2013.

CORRÊA, Roberto Lobato. O espaço Urbano. São Paulo: Ática, 1999.

HONDA, Sibila Corral de Arêa. Habitação de baixa renda como produto do capital: o Programa de Arrendamento Residencial (PAR) em Presidente Prudente. Tese (Doutorado) - Faculdade de Arquitetura e Urbanismo, Universidade Presbiteriana Mackenzie, São Paulo, 2011.

IBGE - Instituto Brasileiro de Geografia e Estatística - histórico de Santo Anastácio, 2016.

\footnotetext{
${ }^{2}$ Levantamentos realizados junto ao cartório de Registro de Imóveis de Santo Anastácio - SP (2017).

${ }^{3}$ Idem.

Colloquium Socialis, Presidente Prudente, v. 01, n. Especial 2, Jul/Dez, 2017, p.794-800. DOI: 10.5747/cs.2017.v01.nesp2.s0230
} 
JALOTO, C. e JUNIOR, A. Santo Anastácio: a história de uma cidade. Porto Alegre: Evangraf ,1995. LACAZE, Jean-Paul. A cidade e o urbanismo. Lisboa: instituto Piaget, 1995

MARICATO, E. Política urbana e de habitação social: um assunto pouco importante para o governo FHC. Revista Praga. São Paulo: HUCITEC, vol.1, n.6, p.67-78, 1998.

SANTOS, Milton. A urbanização brasileira. São Paulo, HUCITEC Ltda, 1993.

SOUZA, Marcelo. Mudar a cidade. Rio de Janeiro: Bertrand Brasil, 2008.

VILLAÇA, Flávio. Espaço intra-urbano no Brasil. São Paulo: Stúdio Nobel, 1998. 